\title{
Towards a Methodological Scheme-InTERPRETATION
}

\author{
[PARA UMA INTERPRETAÇÃO METODOLÓGICA DOS ESQUEMAS MENTAIS]
}

\author{
Hans Lenk* \\ University of Karlsruhe, Germany
}

\begin{abstract}
Any kind of knowledge, cognition, perception, and action is necessarily shaped by (re)activation of "schemata". Any interpretation is schema (re)activation. Schemata are epistemologically speaking "structural" activation patterns which are psychologically and neurologically speaking accommodated, adapted, "learned" by (co- and re)activating neuronal assemblies. Six levels of interpretative schema activations (schema interpretations) are outlined from invariable primary "interpretations" through conventional, classificatory and justificatory as well as metainterpretations. Constitutive schema interpretations are unavoidable. Many philosophical problems will have to be reformulated or reinterpreted along these lines.
\end{abstract} KeYwords: Schemas; perception; knowledge; neurology; psychology
Resumo: Qualquer tipo de conhecimento, cognição, percepção e ação é necessariamente moldado pela (re)ativação de "esquemas". Qualquer interpretação é (re)ativação do esquema. De um ponto de vista epistemológico, os esquemas são padrões de ativação "estrutural", os quais são, psicológica e neurologicamente falando, acomodados, adaptados, e "aprendidos" por (co- e re-) ativação de conjuntos neuronais. Seis níveis de ativação de esquemas interpretativos (interpretações de esquemas) são delineados a partir de "interpretações" primárias invariáveis, tomando por base interpretações convencionais, classificatórias e justificatórias, bem como meta-interpretações. Interpretações de esquema constitutivo são, por isso mesmo, inevitáveis. Muitos problemas filosóficos deverão ser reformulados ou reinterpretados ao longo deste artigo.

Palavras-ChaVe: Interpretações; esquemas mentais; percepção; conhecimento; neurologia; psicologia

ny knowledge avails itself of patterns and structures. In our cognition
of any kind we are obliged to use frames, forms, shapes and constructs as well as schemata or schemes. This is true for all sorts of grasping anything, this may be by a process of recognition and categorization or of normative structuring or planned acting. Applications of forms and frames are schematizations or schema interpretations as I would like to call these interpre(ta)tive constructs and their activation in order to distinguish them from the usual text interpretation in the hermeneutical sense. Schemata might be used consciously or activated

* Professor Dr. Dr. h.c. mult. Hans Lenk. Professor at the Institute of Philosophy at the University of Karlsruhe in Germany, Honorary President of Institut International de Philosophie. Hans Lenk won the gold medal for rowing at the 1960 Rome Olympics. m@ilto: hans@lenknet.de 
subconsciously. Any kind of interpretation whatsoever is connected with or bound to an activation of such schemata.. This connection might be characterized by core features and core stimuli the selection of which is necessary, even though some of these are conducted subconsciously. Even here, on the subconscious level, cognitive quasi-constructs are used to render the profiles of contrast and the structural differentiation by activating the functions of the respective sense organs or their processing units of perception and cognition in the brain as well as the integrating polymodal and combining yet hypothetical centres. They are partly due to hereditary and evolutionary development, partly developed by early ontogenetic interaction with the world, partly learned by experience and instruction.

Generally speaking, I call these abstract constructs of frame character schemata. Schemata are developed and applied on different representational levels in order to integrate individual experiences, single activities and sense data or stimulations into a more general frame, pattern or similarity structure. In any case, whenever we try to combine phenomena and the results of categorizing under generic perspectives, concepts, equalities of form or shape and similarities as well as analogues (analoga) of all these, whenever we try to identify, retrieve, recognize shapes transcending the individual phenomenality of the so-called qualitatively given, we rely on the activation of such schemata. Any recognizing and generalising, particular conceptual knowledge is thus bound to cognitive schemata which can be understood as more or less abstract constructs which are projected onto and into the seemingly direct sense perception and the respective experiences by recognizing Gestalten or constituting objects, processes, events etc. Any seeing and recognizing shapes and forms is dependent on and guided by schemata. Any cognition whatsoever is thus schematic. This is true not only for recognition, but also for actions, i.e. not only for rather passive sorts of "grasping", but also for rather active kinds of grasping.

It was Kant who developed in his Critique of Pure Reason the concept of schema for epistemology by conducting within quasi operational procedures of instantiating as well as developing schemata a connection between sense reception on one hand and conceptual recognition on the other. Kant defined ( $\mathrm{KrV}$ B, 179f, my translation) a schema as "product of the power of imagination (Einbildungskraft), which is not attending to individual images or imaginations, but towards the 'unity' of sensations and intuitions (Anschauungen) and the determination of sensuality", "which is rather the imagination of a method to imagine according to a certain concept in an image than the image itself": "Now, this imagination (Vorstellung) of a general procedure of the power of imagination to render an image for a concept, I call the schema connected with this concept". Kant related the concept of schema as a concept of such an operation of the sensual and conceptual shaping and framing not just to sense perception like the sensing and seeing of figures in visual space, but also to the imaginative substantiation of the "pure concepts of reason" (categories). The respective abstract - "transcendental" schema is "but the pure synthesis, according to a rule of the unity following concepts in general ..." (category) (ibid., p. 181). "In fact, at the foundation of our pure sensual concepts there are not pictures of the objects, but schemata" (ibid.). He terms the procedure, to render to the categories their "image" or mental image, a transcendental schema and calls the respective mechanism of coordination 


\section{transcendental schematism.}

However, Kant applied this procedure of coordination and therefore also the concept of schema also to "imaginative" and mental representation of any objects of experience whatsoever, i.e. of their images: "The image is a product of the empirical capacity of the productive power of imagination, the schema of sensual concepts (being of the figures in space) is a product and so to say a monogram of the pure power of imagination a priori, by which and according to which the images are rendered possible at all, which however have always to be connected with the concept only by using the schema which they designate and with which they per se are not totally congruent" (ibid.).

Kant anticipated the process of developing and establishing as well as applying cognitive constructs for the imaginative realization, visualisation of mental configurations and models, i.e. of cognitions. Cognitive psychology has only since few decades in the wake of theories and concepts of Gestalt psychology rediscovered this concept of schemata as "imaginative" cognitive constructs (cf. e.g. Rumelhart 1978). Schemata are called by Rumelhart "the building blocks of cognition" (1978). Psychology discovered that not only visual conception and sense perception general, but also conceptual and common sense or naive theoretical cognition operates in terms of the developing and applying schemata, i.e., any cognitions, interpretations, knowledge whatsoever are bound to the application, selection and activation as well as checking of schemata (see, e. g., Neisser). The process of interpretation is basically to be seen in the or even as the selection and activation of possible configurations of schemata which are verified under the perspective whether or not they are congruent with thought data-fragments of memory. Beyond that, this process is an active process of searching for and structuring informations.

In general, we use mental representations of frames or data features or contents which are typified, generically distinguished and concentrated to relevant features which are retrievable from memory. One may well ask whether or not the expressions and concepts of "structure", "construct" and similar concepts like "strategy", "script" (after Schank-Abelson, 1977), "frames" (after Minsky and Goffman), "configuration", "conceptual schema" etc. are essentially referring to the same concept, namely schema. There is no explicit, really non-circular definition of 'schema'; therefore Rumelhart concentrates on developing a schema theory which proceeds by giving essential features within hypotheses and thereby an implicit or functional or "operational" definition of the functional concept of "schema".

Rumelhart (ibid., 1978) compares the concept, role, activation and function of a schema with similar concepts of structured activities: for example, schemata are like theater stagings: the instantiation or activation of a schema is like the staging of a drama, the internal structure of the schema referring to the script or plot. Similarly, schemata can be compared with theories, computer programs, parsing analyses in linguistics etc. In all these cases we have procedures and functional shaping of reconstructions which comprise variations, checks, ramifications and extensions as well as a judgement about fitting or falsification, substitution or modification of a construct by another one. It is characteristic that schemata are connected with other schemata and subschemata in a certain hierarchical architecture and that schemata have variables connected with different 
aspects of the environment and the diverse instantiations of the schema. For instance, the schema BUYING admits of the functional roles and schemata of buyer and seller as well as the media money and goods as well as the subschema bargaining. The instantiation of such a schema may indeed be considered as an analogue of the staging of a drama whereas however the concretisation and instantiation of the variables allow for a greater flexibility and openness than the interpretation of a plot by the actor or director.

Schemata however are more abstract and general than a drama or its plot and script. Schemata can also refer to things, objects, shapes and events as well as any spacial, static or functional relationships and constellations whatsoever.

It is important that schemata consist of subschemata. The activation of a subschema is usually immediately related with the activation of the schema itself and the other way around. The comparison of schemata with programs, networks etc. is certainly fruitful and can be visualized in flow charts and related structural means admitting of state and point identification of the constituents and the ramifications of such structures. The total set of the schemata we use to interpret our world comprises in some sense our private theory of the nature of reality. Schemata represent so to speak our internal model of the respective situations in the world: Methodologically speaking, (schema) interpretation is but the (re)activation of schemata. It is true that according to modern cognitive psychology the interpretative structuring of sense perception the comprehension of texts as well as memorising and the solution of problems is essentially dependent on the selection, (re)activation and instantiation of schemata. But not only the interpretation of a situation, but also active information seeking as well as the integration into contexts and the development of strategies for problem solving will follow the lead of partly concept-guided, partly data-guided application of schemata. The mutual activation of schemata and subschemata is essential. In general, the concept of schema or cognitive construct or even interpretational construct is a rather fruitful instrument for developing a cognitive psychological theory, but beyond that also for a new methodological epistemology. Cognitive constructs, schemata and interpretational constructs are really "the building blocks of cognition" (Rumelhart 1978) and of any mental representation or information manipulation. As Kant already recognized the dynamical and structural as well as functional visualization of abstract constructs is schema dependent and this is not only true for empirical procedures of grasping, i.e. cognition and action, but also for methodological constructs. One may develop a sort of non-foundational transcendental philosophy of the fundamental conditions of any development, application and stabilization of any procedures of structuring by any kind of representation, be it by frames, concepts, orders, unifications, configurations etc. Interpretation is, generally speaking, the development, stabilization and activation (application) of mentally representing constructs or schemata. Interpretation (in a wide sense) is basically schema interpretation and founded on this as well as grounded in schema activation. Therefore, I talk of schema interpretation. We can even conceive of a basic axiom or principle of methodological interpretationism stating that all kinds of grasping, cognition and action are interpretation dependent, i.e. founded on the activation of schemata. This is true far beyond psychological theories and epistemological perspectives, but rather a totally general methodological comprehensive approach 
comprising the philosophy of knowledge (traditionally called epistemology) as well as philosophy of action and representation. We can call this approach a methodological and transcendental construct or schema interpretationism overarching even the modern split between natural and social sciences as well the humanities, since all these disciplines would structure their fields and objects according to the activation of schemata by using procedures of establishing, stabilizing and activating schemata as cognitive constructs in order to structure the respective world versions and sets of objects or events, structures, procedures as well as projections.

It is interesting that schema interpretation admits of levels of categorisation as well as according to the variability of the respective schemata, i.e. whether or not they are hereditarily fixed or conventionalized or flexible, whether they are subconsciously developed and activated or consciously conceived and used. I developed a hierarchy of levels of interpretation consisting of six different levels or plains of interpretation. The following diagram shows the respective six $1 x$ levels:

\section{DiAGRAM OF THE LEVELS OF INTERPRETATION}

IS $_{1}$ : practically unchangeable productive primary interpretation ("Urinterpretation") (primary constitution or schematization, respectively)

$\mathrm{IS}_{2}$ : habit-shaping, (equal) forms-constituting pattern interpretation (ontegenetically habitual(ized) form and schema categori(ali)zation and preverbal concept-formation)

$\mathrm{IS}_{3}$ : conventional concept formation transmitted by social, cultural and norm-regulated tradition

$\mathrm{IS}_{3 \mathrm{a}}: \ldots$ by non-verbal cultural gestures, rules, norms, forms, conventions, implicit communicative symbols

$\mathrm{IS}_{3 \mathrm{~b}}: \ldots$ by verbal forms and explicitly representing communicative symbols, metasymbols, metaschemata etc.

IS4: applied, consciously shaped and accepted as well as transmitted classifactory interpretation (classification, subsumption, description by "sortals", generic formation of kinds, directed concept-formation)

$\mathrm{IS}_{5}$ : explanatory and in the narrow sense "comprehending" ("verstehende"), justifying, theoretically or argumentatively 


\section{substantiating interpretation, justificatory interpretation}

IS $_{6}$ : epistemological (methodological) metainterpretation (plus metameta-interpretation etc.) of methods, results, instruments, conception of establishing and analysing interpretative constructs themselves

The different levels of interpretation are the following ones: IS $_{1}$ comprises the practically unchangeable productive primary interpretations of primary constituation which might be represented by subconscious schema instantiation. They comprise the hereditarily fixed or genetically founded activation of selective schemata of sense perception (e. g. contrasts of dark and light etc.) as well as the interactive, selective activations of early ontogenetic developments like the stages of developmental psychology discussed by Piaget. Also comprised are the biologically hardwired primary theories which we cannot alter at will, but which we can (only) problematize in principle. For instance we have no magnetic sense or capacity to trace ultrasound like the bats. But we can conceive of conditions in which we could have these senses or at least devise technological means for substituting these. - On the second level we have the habitual, quality forming frame interpretations and schema categorisations as well as categorializations which are abstracted from prelinguistic discriminatory activities, experiences of equality of shape, similarity of presentation and experience etc. Establishment and discriminatory capacity of prelinguistic conceptualization and development of concepts about language is to be formed on this level. - On level $\mathrm{IS}_{3}$ we have conventional concept formation, namely socially and cultural traditional conventions and norms for representation and forms of discriminatory activities like the explicit conceptualization of framing the world according to natural kinds etc. In so far as this is not related already to language differentiation we can think of a sublevel $\left(\mathrm{IS}_{3 \mathrm{a}}\right)$ on which prelinguistic conventionalizations are characteristic. On the other hand (on $\mathrm{IS}_{3 \mathrm{~b}}$ ) we have the explicitly linguistic conventionalization or the differentiation of concepts by means of language. - Level 4 would comprise the consciously formed interpretations of embedding and subsuming as well as classifying and describing according to generic terms, kinds etc. It is the level of ordered concept formation and classification as well as ordering and subsumption. Level IS ${ }_{5}$ would go beyond that by rendering explanatory, or in the narrower sense comprehending ("Verstehen") interpretations as well as justifying a theoretically argumentative interpretations in a sense of looking for reasons and grounds of justification.

These activities are certainly not only advanced in science and intellectual disciplines but in any case also in every day life and common sense. Any kind of a systematic comprehension within the compounds of theories, systems and overarching perspectives of integration is important here.

Beyond that however, we have also a level ( $\mathrm{IS}_{6}$ ) of the epistemological and philosophical as well as methodological interpretations of a meta-character, overarching and integrating the procedures of theory building and theory interpretation, methodology and the models of interpretation in the sense of methodological schema interpretationism itself. One could call this a metalevel of 
interpretativity and talk about epistemological metainterpretations. However, this level is cumulative and can be considered as being open towards further metalevels. The model and approach of epistemological interpretationism is itself certainly an interpretative one and can be described and developed only on a certain respective meta-level which is to be seen within the level $\mathrm{IS}_{6}$. Therefore, we have the possibility of a self-application of the interpretational method to interpretatory procedures itself. The philosophy of schema interpretation is a philosophy of interpretational constructs as an epistemological model which admits of a certain kind of metatheoretical and metasemantical self-application in the form of a sort of "metainterpretation". This is certainly an asset and epistemological advantage compared to a few other epistemological approaches including critical rationalism after Popper, a theory which does not admit and conceive of the precise conditions of being falsified itself. The human being is indeed the "meta-interpreting being" (cf. my 1955), capable of ascending to ever higher metalevels of (schema)interpretation.

If we use these levels and metalevels of interpretational constructs we can reinterpret many of the traditional philosophical problems and reformulate them with respect to the relationship between different interpretational levels as mentioned. This is true, e.g. for the concept of truth according to the correspondence theory as well as the consensus or pragmatic theory as well as many other central problems like the problem of meaning, the problem of reference and even the problem of content and intentionality as well as the old-fashioned problem of realism. The latter one can be solved now with respect to what may be called a pragmatic interpretational realism on which we have to rely for practical and common-sense-life reasons.

In addition, we can so to speak interpretationally relativise the problem of the reality of the world by discussing it under the perspectives of the different levels of interpretation as sketched out above. Certainly we have to dispense with absolute foundationalism in philosophy and epistemology. But in any case, the differentiation between reality and the interpretational representation of it is still relevant under the auspices of the above-mentioned axiom of the all-pervasive interpretativity and interpretation-impregnatedness of everything which is "grasped" or even conceived by delineating an interpretative relationship between the respective level or meta-level of interpretational constructs and postinterpretationist distinction between the concepts, framings etc. on the one hand and "things", "objects" and so on on the other hand. We can talk of a certain pragmatic or practical realism not only for common sense reasons, but also from the perspective of a methodological interpretationism of a quasi transcendental character which allows of a relativised realistic position. This realism is certainly not a naive one, but a critically and interpretationally broken or really schema interpretation-impregnated one. Any realism whatsoever is to be restricted from an interpretational perspective in so far as we have no pure unbiased knowledge of the hypostatized world (any hypostatizing is necessarily schema interpretative). We have to recognize that all our graspings of reality are but shaped, impregnated, established and prestructured by our different sorts of schema interpretations starting from primary ones to more conventional ones (this might be considered a Kantian approach which also is to be found in internal realism as developed by 
Putnam).

Secondly, we have to acknowledge, that methodologically speaking even the distinction and differentiation between the "real" world and the interpreting being, the interpreting "self" or traditional transcendental subject, are per se a result of

18 such an epistemological interpretation. The quasi dualistic model of distinguishing and differentiating between "world" and the "self" is - judged from a higher level (e. g. $\mathrm{IS}_{4}$ through $\mathrm{IS}_{6}$ ) - an interpretational model2x. The same is true for the distinction and differentiation between knowledge and action etc. We can only represent "something" and operate within our interpretational bounds, so to speak from certain interpretational perspectives, under the auspices of applying and using interpretational methods and methodologies.

In short: The indispensability of schema interpretation is beyond any doubt and discussion. Any knowledge and grasping in the active and passive sense of the term, any comprehension of something as something - be it ideal or real or whatever - is dependent on interpretational forms and structures, in short: on interpretational constructs and schema interpretations. Any reality whatsoever, any ideal object and object of the activity of meaning something can possibly only be captured or grasped in schema-interpretative forms and frames and is therefore necessarily to some degree interpretation-dependent, interpretation-imbued, constituted and only constitutable by interpretational means. It is perspectival without - as in the case of impregnations (see latest note above) - necessarily being totally relativistic. However, schema interpretation itself is but an epistemological means of interpreting. It is itself an interpretative construct or activity, namely under the auspices of a pragmatic interpretational methodology, which can possibly be combined with a pragmatic realism. Schema interpretation is not everything, but anything conceivable is perspectivally interpretation-dependent or in the more specific sense interpretation-laden, if not even - as again in the case of direct perception - schema interpretation-impregnated in the narrower sense. Everything can only be grasped by means of schema interpretation, i. e. by constituting schema and developing as well as activating and reactivating schemata, in short, by schema interpretation. Any "grasping" of anything whatsoever (be it seemingly passively in the form of perception or "impregnation" in the narrower sense by factors of the 'external world' or be it more actively by framing thoughts and actions) is formed, influenced or externally impregnated by schema selection and activation.

Interestingly enough, modern neuroscience is on the brink of giving a naturalized theory of schema development, schema activation and stabilization as well as schema reactivation. Brain researchers think of the brain as an interpretative system" (Roth, 1992, 120, 1994) or of "brain constructs" ("Hirnkonstrukte") (Singer, 1990, 8) which are based on the establishment and development of plastic (i. e. flexible though relatively stabilized) neuronal assemblies (von der Malsburg 1986, cf. also Rakic-Singer 1988). The forming and the establishment of neuronal assemblies is hypothesized as being a building-up and stabilization of the frequency phases of oscillatory reactions of different overlapping co-varying and cooscillating neuronal entities and the neuronal assemblies or networks which are activated simultaneously and selectively on adapting to a certain rhythmic ground oscillation of $40 \mathrm{Hertz}$ and a respective process of synchronization of these 
oscillations which are starting to oscillate in common phase. Such a theory of the synchronicity of building up and dynamically stabilizing a certain kind of oscillation pattern and initiated impulses in the physical sense seems to be a potential explanation for the recognition of patterns, representations of forms and recognition of mental states of activities as well as mental imaginations and retrievals from memory. Therefore, we have special grounds to hypothesize about the neural biological and neurophysiological foundations of the schematization processes and establishment of constructs within the brain and in interaction with the external environment of stimuli and representational 'encodings' as well as "active" interaction and intervention with it. This can also be related to the development of neurons and perceptual as well as cognitive capacities in developmental psychology and physiology, cognitive science and neuroscience and may potentially render a naturalized basis of the processes of formation of knowledge, perception and cognition in general. I don't think, that all semantical programs of meaning and epistemological problems of intentionality can be naturalized in the strict sense. We are not yet able fully to straddle the "semantic lacuna" - even not in teleological-functional approaches like Millikan's (1984) well elaborated one.

Even natural scientists in modern fields like microphysics, in dealing with theoretical entities avail themselves of interpretational constructs as we all do in our everyday life, too. Therefore, the cleavage between natural sciences and interpretative disciplines, the gap between reality and representation, between knowledge and action, between experimental results and the pre-experimental setup, between concept formation on the one hand and referents of concepts on the other is not as wide as we would traditionally think. Knowledge and action are connected and overlapping, they are but perspectival differentiations of one another under a certain emphasis. Intervention into the world is always dependent on interpretation and the other way around. Interpretation in general and the capacity to interpret is dependent on impregnation in the narrower sense, that is on the fact that hypostasized "real" worldly structures have an impact on our actions and reactions as well as our modes and means of representation. Intervention, interpretation and impregnation are mutually related, even the distancing of "the world" from our acting and recognizing, from cognition and knowledge is gradual, relativized, itself in a sense interpretation-dependent, at least from an epistemological perspective.

\section{REFERENCES}

ABEL, G., Interpretationswelten. Frankfurt/M.: Suhrkamp 1993.

GOFFMAN, E., Rahmen-Analyse. Frankfurt/M. 1977 (Orig. 1974).

KANT, I., Kritik der reinen Vernunft. 2. Auflage 1787. (KrV B) Hamburg: Meiner 1956.

LENK, H., $\mathrm{Zu}$ einem methodologischen Interpretationskonstruktionismus. In: Journal for General Philosophy of Science 22 (1991), 283-302.

LENK, H., Interpretationskonstrukte. Zur Kritik der interpretatorischen Vernunft. Frankfurt/M.: Suhrkamp, 1993.

LENK, H., Philosophie und Interpretation. Frankfurt/M.: Suhrkamp, 1993.

LENK, H., Toward a Systematic Interpretationism. In: Stapleton, T. J. (Ed.), The Question of Hermeneutics. Dordrecht: Kluwer, 1994, 79-88.

LENK, H., Interpretation und Realitaet. Frankfurt/M. 1995, Suhrkamp.

LENK, H., Schemaspiele. Frankfurt/M.: Suhrkamp 1995. 
LENK, H., Das metainterpretierende Wesen. In: Allgemeine Zeitschrift für Philosophie 20.1 (1995a), 39-47.

LENK, H., Interpretationen und Impraegnationen. in: Simon, J. (Ed.), Orientierung in Zeichen. Frankfurt/M.: Suhrkamp 1997, 19-40.

MALSBURG, C. von der, Am I Thinking Assemblies? In: Palm, G. - Aertson, A. (Eds.), Brain

20 Theory. Heidelberg/New York: Springer 1986, 161-176. 1984.

MINSKY, M., Frame-System Theory. In: Schank, R. C. - Nash-Weber, B. L. (Eds.), Theoretical Issues in Natural Language Processing. 1975 (reprint MIT). Also in: Johnson-Laird, P. N. - Wason, P. C. (Eds.), Thinking. Cambridge 1977.

NEISSER, U., Cognitive Psychology. New York: Meredith 1966.

NEISSER, U., Cognition and Reality, N. Y. 1976.

RAKIC, P. - Singer, W. (Eds.), Neurobiology of Neocortex. In: Dahlem Workshop Reports. Chichester: Wiley, 1988.

ROTH, G., Kognition: die Entstehung von Bedeutung im Gehirn. In: Krohn, W. - Küppers, G. (Eds.), Emergenz: Die Entstehung von Ordnung, Organisation und Bedeutung. Frankfurt/M.: Suhrkamp 1992, 104-133.

RROTH, G., Das Gehirn und seine Wirklichkeit. Frankfurt/M.: Suhrkamp 1994.

RUMELHART, D. E., Schemata: The Building Blocks of Cognition. Center for Human Information Processing, University of California, San-Diego-La Jolla, quoted after CHIPReport 79, 1978 (also in Spiro, R. - Bruce, B. - Brewer, W. (Hg.), Theoretical Issues in Reading Comprehension. Hillsdale NJ 1980).

SCHANK, R. C. - Abelson, R., Scripts, Plans, Goals, and Understanding. Hillsdale NJ: Earlbaum 1977.

SINGER, W. (Ed.), Gehirn und Kognition, Special Issue of Spektrum der Wissenschaft. Heidelberg 1990. 